\title{
Phytochemical and Antioxidant Capacity of Traditional Rice Varieties of Karnataka, India
}

\author{
Gopika C. Muttagi* and Usha Ravindra \\ Department of Food Science and Nutrition, UAS, GKVK, Bengaluru, India \\ *Corresponding author
}

\begin{abstract}
A B S T R A C T
Keywords

Traditional rice varieties, phytochemical, antioxidant

Article Info

Accepted:

05 April 2020

Available Online:

10 May 2020

Evaluation of twenty traditional rice varieties grown in Karnataka, as a dehusked grain was performed with respect to Phytochemical and Antioxidant capacity. Traditional rice varieties varied significantly $(\mathrm{p}<0.05)$ for all the parameters studied. Phytochemicals namely, phytic acid, tannic acid and total polyphenol content were studied in twenty traditional rice varieties varied significantly $(\mathrm{p}<0.05)$ from 236.94 to $558.67 \mathrm{mg}, 25.74$ to $56.88 \mathrm{mgGAE}$, and 47.82 to $160.71 \mathrm{mg}$ per $100 \mathrm{~g}$ respectively. Total antioxidant capacity varied significantly from $257.93 \mu \mathrm{M}$ to $800.25 \mu \mathrm{M}$ ascorbic acid equivalent per $100 \mathrm{~g}$. Traditional rice varieties contained good amount of phytochemicals and antioxidant activity which are helpful in maintaining good health and wellness.
\end{abstract}

\section{Introduction}

Rice (Oryza sativa L.) is one of the major food crops in the world and more than 50 per cent of the world's population depend on rice as their primary calorie source (FAO, 2001) and increasingly becoming popular because of its nutritional and beneficial health properties (Saikia et al., 2012). Commonly, rice is consumed as polished white rice with the husk, bran, and germ fractions removed. However, consumption of brown rice (hulled rice) is increasing in recent years, due to the increased awareness about its health benefits and good nutritional properties due to higher amounts of proteins, ash, dietary fibre and minerals than white rice (Tan et al., 2009; Mohan et al., 2010; USDA, 2010).

Rice bran contains high amounts of protein, fiber, minerals, vitamins, phytochemicals, bioactive molecules, tocopherols, tocotrienols, oryzanols and other phenolic compounds (Yokoyama, 2004; Wanyo et al., 2009; Mohan et al., 2010; Zhu et al., 2010; Min et al., 2011). Phytochemical's functions 
include free radical scavenging, antioxidant activity, enhancement of immune systems, and reduction of the risk of developing heart disease and cancer (Qureshi et al., 2000; Xu et al., 2001). Through the introduction of modern high yielding varieties, along with new management practices and green revolution has led to a considerable increase in rice production in India as in other Asian countries. This development has led to a gradual erosion of the rice genetic diversity, since thousands of traditional rice varieties were replaced by relatively few high yielding rice varieties (Rahman et al., 2006).

Traditional rice varieties have long been consumed in Asian countries e.g., India, Sri Lanka, China, Japan, etc. (Ahuja et al., 2007; Finocchiaro et al., 2007; Finocchiaro et al., 2010). Being a major cereal grain, evaluating the nutritional composition of rice has been given highest priority (Dong et al., 2007). Rice grain quality is reported to be influenced by various physico-chemical and cooking characteristics (Bocevska et al., 2009; Moongngarm, 2010). Providing adequate information on the quality of rice consumed by local population is important for health conscious consumer. Variety with best grain properties remains the most important determinant of market grading and end use qualities. However, studies have not been carried out comprehensively on phytochemical and antioxidant capacity of the traditional rice varieties in Karnataka, India.

To encourage traditional rice cultivation in India, there is need for a systematic study that would reveal nutritional qualities from traditional rice varieties and would stand the world market competitiveness. Thus keeping in view of above facts the present research work was undertaken with the objective to analyse phytochemical and antioxidant capacity of traditional rice varieties of Karnataka.

\section{Materials and Methods}

\section{Procurement of traditional paddy rice varieties}

Twenty traditional rice varieties procured from All India Coordinated Research Project on Rice, ZARS, V. C. Farm, Mandya, Karnataka were included in this study. The different genotypes used for the study are, Gamnad batta, Anandi, Krishnaleela, Kagisaale, Murakan sanna, Mysore mallige, Nagabatta, Gajagunda, Doddabyranellu, Ratnachoodi, Malgudi sanna, Gowrisanna, Chinna ponni, Salem sanna, Karimundaga, Rajmudi, Rajakaime, Jeerige sanna, Gandhasaale, Kalajeera.

\section{Milling of paddy varieties}

Paddy samples were cleaned thoroughly using winnower to remove the chaff and other foreign matters and dried in hot air oven up to 12-14\% moisture content and de-husked using a rubber roll paddy sheller at the Department of Post-harvest Technology, UAS, GKVK, Bengaluru. Milling fractions include husk, head rice, bran, and broken rice.

Only whole rice grains without any physical damage or insect infestation were selected for study purpose. Further, rice samples (head rice without polishing) were individually ground to a fine powder (60 mesh size), packed in air tight polyethylene plastic bags and were stored at $4{ }^{\circ} \mathrm{C}$ until further analysis.

\section{Rice grain classification}

Milled rice was first classified into three categories based on length, long ( $>6 \mathrm{~mm})$, medium $(5-6 \mathrm{~mm})$, and short $(<5 \mathrm{~mm})$. They were again classified into three groups based on the length/breadth ratio; slender ( $>3)$; bold $(2-3)$; round $(<2)$ to determine size and shape (IRRI, 1993). 
Estimation of phytochemical and antioxidant capacity

The pytochemicals such as phytic acid, tannin, total polyphenol content, and antioxidant activity were estimated. The methods adopted for phytochemicals analysis are as follows.

\section{Estimation of phytic acid}

The estimation of phytic acid was based on the principle that the phytate is extracted with trichloroacetic acid and precipitated as ferric salt. The iron content of the precipitate was determined colorimetrically and the phytate phosphorous content calculated from this value assuming a constant $4 \mathrm{Fe}$ : 6 molecular ratios in the precipitate. Phytates were estimated as phytic acid (Sadashivam and Manickam, 1991).

\section{Estimation of tannin (AOAC, 1980)}

Tannin was estimated colorimetrically based on the measurement of blue colour formed by the reaction of phosphotungstomolybdate acid in alkali solution.

\section{Estimation of total polyphenols}

Blue colour developed by polyphenols with FCR reagent in alkaline condition was measured at $650 \mathrm{~nm}$ (Sadasivam and Manickam, 1991).

$\begin{gathered}\text { Total } \\ \begin{array}{c}\text { polyphenol } \\ (\mathrm{mg} / 100 \mathrm{~g})\end{array}\end{gathered}=\frac{\begin{array}{c}\text { Concentration of } \\ \text { polyphenol from } \\ \text { graph }\end{array}}{\begin{array}{c}\text { Aliquot taken for } \\ \text { estimation }\end{array}} \times \frac{5}{\begin{array}{c}\text { Wt. of } \\ \text { sample }\end{array}}$

\section{Estimation of antioxidant activity by DPPH} method

The antioxidant activity was expressed in terms of ascorbic acid equivalents, so ascorbic acid was taken as substrate. Various concentrations of ascorbic acid were prepared and added to DPPH solution. The decrease in O.D is plotted against concentration of ascorbic acid. The concentration of sample was calculated using the standard curve (Brand-Williams et al., 1995).

\section{Results and Discussion}

\section{Phytochemical composition and antioxidant capacity}

Phytochemicals viz., phytic acid, tannic acid and total polyphenol content that were studied in twenty traditional rice varieties are reported in Table 1. Total antioxidant capacity (TAC) expressed by ascorbic acid equivalent (AAE) in long, medium and short grain rice varieties are also presented in Fig. 1. The relationship between TAC and TPC is depicted in Fig 2.

\section{Phytic acid (per 100g)}

The twenty rice varieties tested had a large variation in contents of phytic acid and statistically significant differences $(p<0.05)$ were observed between the rice varieties. Irrespective of grain category, the amount of phytic acid content ranged between 236.94 and $558.67 \mathrm{mg}$ per $100 \mathrm{~g}$. Among long grain rice varieties Krishnaleela $(540.62 \mathrm{mg})$ reported the highest phytic acid followed by Gajagunda (543.42) with no significant difference while least value was recorded in Anandi $(250.50 \mathrm{mg})$.

Among medium and short grain rice varieties, Doddabyranellu (558.67 mg) and Kalajeera (348.78 mg) recorded higher level of phytic acid while least was observed in Chinna ponni (236.94 mg) and Rajakaime $(264.90 \mathrm{mg})$ respectively. Overall, Doddabyranellu $(558.67 \mathrm{mg}$ ) had highest phytic acid content and least was in Chinna ponni (236.94 mg). 
The variation in phytic acid among traditional rice varieties probably due to differences of cultivating environments and agricultural practices (Liu, 2004). In this study, Doddabyranellu (558.67 $\mathrm{mg})$ had highest phytic acid content and least was in Chinna ponni (236.94 $\mathrm{mg}$ ) among all the traditional rice varieties. Liang et al., (2008) reported that phytic acid levels in brown rice ranged from 7.8 and $11.1 \mathrm{~g}$ per $\mathrm{kg}$ and decreased with prolonged milling.

However, phytic acid levels in milled rice ranged from 0.2 to $9.0 \mathrm{~g}$ per $\mathrm{kg}$. These results are in agreement with Almana (2000) who reported that, the lower phytate content of milled rice was due to the separation of bran layer and aleurone layer of the kernel. In this study, lower values of phytic acid were observed. However phytic acid values are comparable with the values reported by Shallan et al., (2010).

\section{Tannic acid (per 100g)}

Tannic acid is a type of polyphenol. The means of tannic acid differed significantly $(p<0.05)$ among long grain rice varieties, the lowest values being found in the Gamnad batta $(25.74 \mathrm{mg})$ and the highest in Gajagunda $(54.13 \mathrm{mg})$. Medium grain rice varieties ranged from $29.98 \mathrm{mg}$ (Chinna ponni) to $56.88 \mathrm{mg}$ (Karimundaga) for tannic acid and $28.65 \mathrm{mg}$ (Kalajeera) to $42.29 \mathrm{mg}$ (Rajakaime) in short grain rice varieties.

Irrespective of grain type, Karimundaga (56.88 $\mathrm{mg}$ ) recorded maximum tannic acid, whereas Gamnad batta (25.74 mg) recorded minimum. The results obtained in the present study are in accordance with the values reported by Trinidad et al., (2009). In their study, tannic acid contents in brown rice (56.9 $\pm 3.2 \mathrm{mg} / 100 \mathrm{~g}$ ) was significantly higher than milled rice $(21.3 \pm 2.3 \mathrm{mg} / 100 \mathrm{~g}, \mathrm{P}<0.05)$.

\section{Total polyphenol content (GAE per $100 \mathrm{~g}$ ))}

Phenolic compounds are one of the major and most complex groups of phytochemicals in cereal grain. Great interest has been shown in the polyphenols in rice for their multiple biological activities. Total polyphenol content (TPC) expressed in terms of gallic acid equivalent (GAE) per $100 \mathrm{~g}$ of rice was found significantly $(\mathrm{p}<0.05)$ highest in Gajagunda $(152.33 \mathrm{mg})$ and lowest was observed in Nagabatta $(47.82 \mathrm{mg}$ ) among long grain rice varieties.

Karimundaga (160.71 mg) a medium grain rice variety showed significantly highest TPC among all the varieties tested. TPC ranged between 55.27 and $82.79 \mathrm{mg}$ in short grain rice varieties. The total phenolics reported by Shao et al., (2014) in fully matured white, red and black rice ranged between 30.69 to $156.83 \mathrm{mg}$ GAE per $100 \mathrm{~g}$ rice.

\section{Total antioxidant capacity (AAE per 100g)}

The beneficial effects originating from phenolic compounds can be a major determinant of antioxidant activities in many edible sources (Lee et al., 2005). The results clearly showed that traditional rice varieties possessed significantly $(\mathrm{p}<0.05)$ higher antioxidant capacity and great variations in all the tested rice varieties (Fig 1). Among long grain rice varieties, it ranged between 257.93 $\mu \mathrm{M}$ (Nagabatta) and $703.76 \mu \mathrm{M}$ (Gajagunda).

Whereas in medium and short grain rice varieties, it varied from $342.58 \mu \mathrm{M}$ (Malgudi sanna) to $800.25 \mu \mathrm{M}$ (Karimundaga) and $275.44 \mu \mathrm{M}$ (Rajakaime) to $431.83 \mu \mathrm{M}$ (Jeerige sanna) of rice respectively. Irrespective of grain type, total antioxidant capacity recorded highest in Karimundaga $(800.25 \mu \mathrm{M})$ and least was in Nagabatta $(257.93 \mu \mathrm{M})$. 
Table.1 Phytochemical composition and antioxidant capacity of traditional rice varieties

\begin{tabular}{|c|c|c|c|c|c|c|}
\hline Category & No. & Varieties & $\begin{array}{c}\text { Phytic acid } \\
\text { (mg/100g) }\end{array}$ & $\begin{array}{c}\text { Tannic acid } \\
\text { (mg/100g) }\end{array}$ & $\begin{array}{c}\text { Total polyphenol } \\
\text { content } \\
\text { (mg GAE/100g) }\end{array}$ & $\begin{array}{c}\text { Total antioxidant } \\
\text { capacity } \\
(\mu \mathrm{M} \text { AAE } / 100 g)\end{array}$ \\
\hline \multirow{8}{*}{$\begin{array}{l}\text { Long } \\
\text { grain }\end{array}$} & 1 & Gamnad batta & $380.24 \mathrm{i}$ & $25.74^{\mathrm{i}}$ & $57.71^{\mathrm{q}}$ & $298.05^{\mathrm{r}}$ \\
\hline & 2 & Anandi & $250.50^{\mathrm{p}}$ & $28.63^{\mathrm{hi}}$ & $78.16^{\mathrm{m}}$ & $361.80^{\mathrm{m}}$ \\
\hline & 3 & Krishnaleela & $540.62^{b}$ & $43.20^{\mathrm{bcd}}$ & $147.45^{\mathrm{d}}$ & $653.98^{d}$ \\
\hline & 4 & Kagisaale & $324.95^{1}$ & $37.44^{\text {def }}$ & $98.16^{f}$ & $622.55^{\mathrm{e}}$ \\
\hline & 5 & Murakan sanna & $430.13^{h}$ & $36.39^{\mathrm{ef}}$ & $84.26^{i}$ & $459.07^{i}$ \\
\hline & 6 & Mysore mallige & $468.66^{\mathrm{g}}$ & $29.09^{\text {ghi }}$ & $90.16^{\mathrm{h}}$ & $485.71^{\mathrm{h}}$ \\
\hline & 7 & Nagabatta & $290.74^{\mathrm{n}}$ & $33.58^{\text {fgh }}$ & $47.82^{\mathrm{s}}$ & $257.93^{\mathrm{t}}$ \\
\hline & 8 & Gajagunda & $543.42^{b}$ & $54.13^{\mathrm{a}}$ & $152.33^{\mathrm{c}}$ & $703.76^{c}$ \\
\hline \multirow{8}{*}{$\begin{array}{l}\text { Medium } \\
\text { grain }\end{array}$} & 9 & Doddabyranellu & $558.67^{\mathrm{a}}$ & $55.26^{\mathrm{a}}$ & $156.72^{b}$ & $750.06^{b}$ \\
\hline & 10 & Ratnachoodi & $500.50^{d}$ & $44.33^{b c}$ & $91.87^{\mathrm{g}}$ & $514.99^{\mathrm{g}}$ \\
\hline & 11 & Malgudi sanna & $500.37^{d}$ & $47.57^{b}$ & $77.68^{\mathrm{m}}$ & $342.58^{\circ}$ \\
\hline & 12 & Gowrisanna & $490.35^{\mathrm{e}}$ & $33.26^{\text {tgh }}$ & $80.32^{1}$ & $398.38^{1}$ \\
\hline & 13 & Chinna ponni & $236.94^{q}$ & $29.98^{\text {ghi }}$ & $112.65^{\mathrm{e}}$ & $574.45^{\mathrm{f}}$ \\
\hline & 14 & Salem sanna & $288.12^{\mathrm{n}}$ & $37.12^{\text {def }}$ & $71.57^{\circ}$ & $354.75^{\mathrm{n}}$ \\
\hline & 15 & Karimundaga & $507.49^{c}$ & $56.88^{\mathrm{a}}$ & $160.71^{\mathrm{a}}$ & $800.25^{\mathrm{a}}$ \\
\hline & 16 & Rajmudi & $478.30^{f}$ & $38.30^{\text {cdef }}$ & $81.41^{\mathrm{k}}$ & $415.39^{\mathrm{k}}$ \\
\hline \multirow{7}{*}{$\begin{array}{l}\text { Short } \\
\text { grain }\end{array}$} & 17 & Rajakaime & $264.90^{\circ}$ & $42.29^{\text {bcde }}$ & $55.27^{\mathrm{r}}$ & $275.44^{\mathrm{s}}$ \\
\hline & 18 & Jeerige sanna & $319.60^{\mathrm{m}}$ & $35.31^{\mathrm{fg}}$ & $82.79^{j}$ & $431.83^{j}$ \\
\hline & 19 & Gandhasaale & $329.94^{\mathrm{k}}$ & $34.17^{\text {fgh }}$ & $62.52^{p}$ & $313.13^{q}$ \\
\hline & 20 & Kalajeera & $348.78^{j}$ & $28.65^{\mathrm{hi}}$ & $73.52^{n}$ & $332.18^{p}$ \\
\hline & & F test & $*$ & $*$ & $*$ & $*$ \\
\hline & & SEm \pm & 1.614 & 2.237 & 0.323 & 0.489 \\
\hline & & $\mathrm{CD}$ at $5 \%$ & 4.475 & 6.202 & 0.894 & 1.356 \\
\hline
\end{tabular}

* Significant at $5 \%$ level

Note: Means in the same column followed by different superscript letters differ significantly 


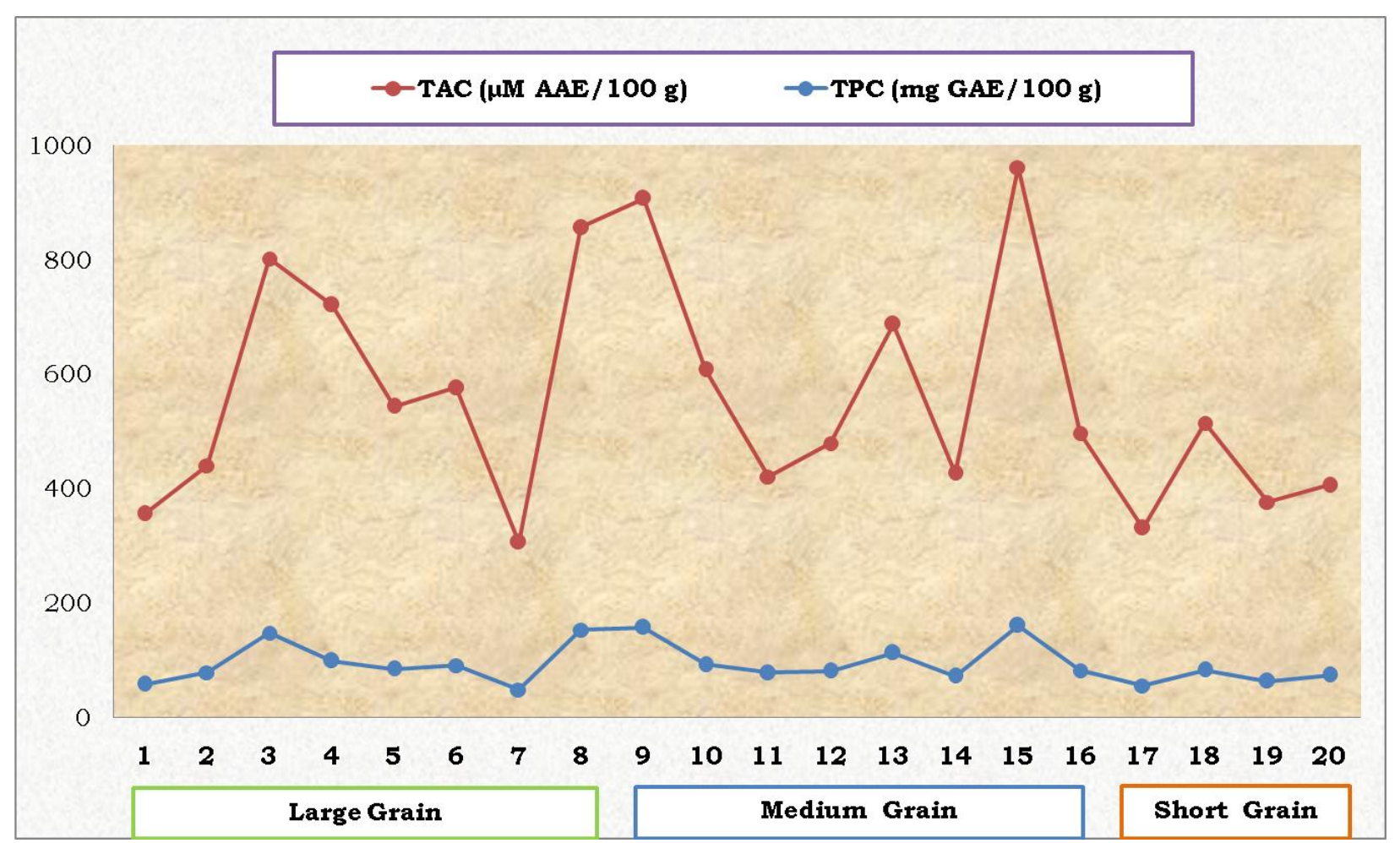

Fig.1 Total polyphenol content (TPC) and total antioxidant capacity (TAC) of traditional rice varieties

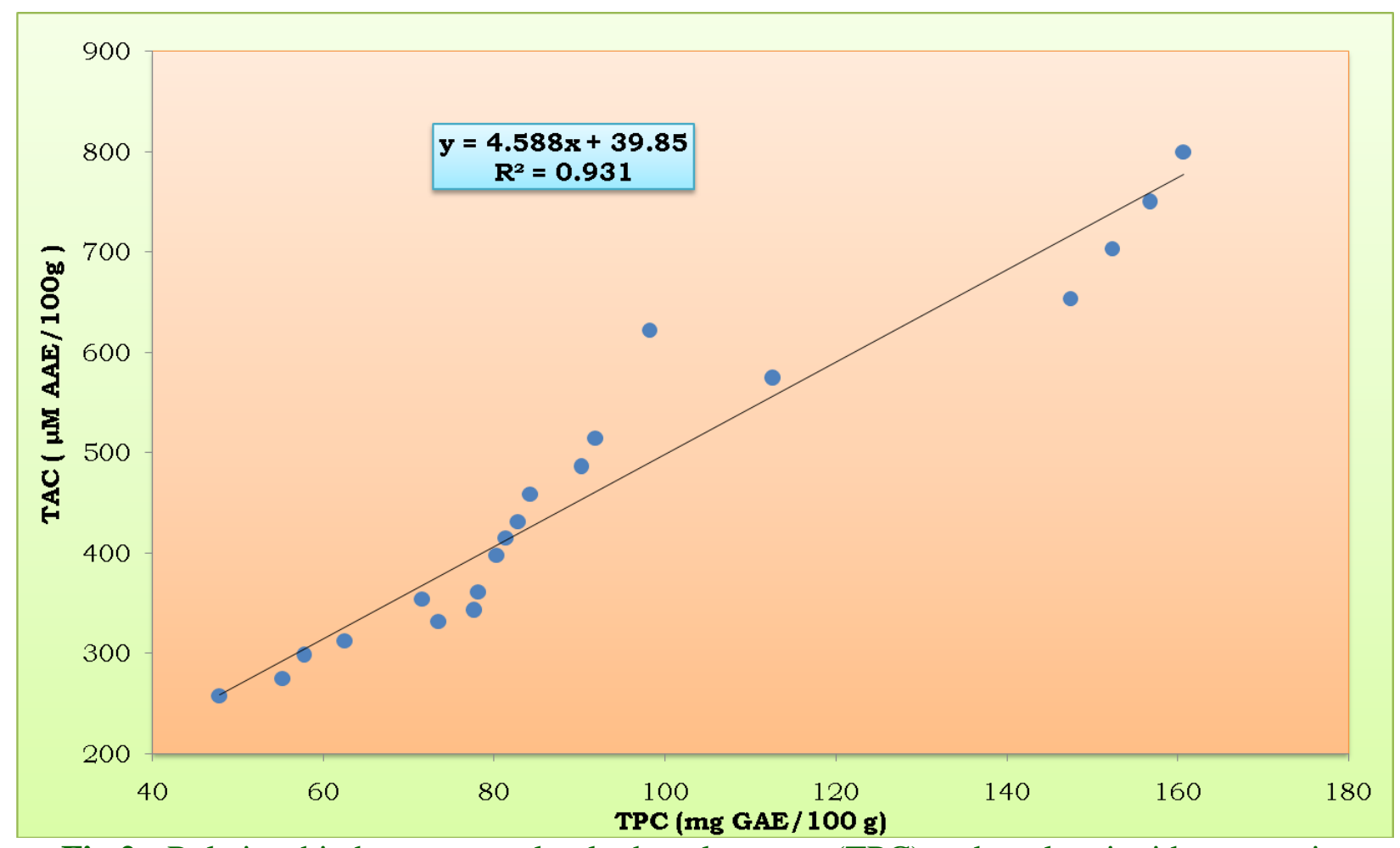

Fig.2 Relationship between total polyphenol content (TPC) and total antioxidant capacity (TAC) of traditional rice varieties 
Dutta et al., (2012) reported total antioxidant capacity in methanolic extracts of ten high yielding rice varieties of Bangladesh ranged from 297.04 to $701.16 \mu \mathrm{M}$ AAE per $100 \mathrm{~g}$ of dry weight of rice flour. Similar results were obtained in the present study and clearly showed that traditional rice varieties possessed significantly $(\mathrm{p}<0.05)$ higher antioxidant capacity expressed in terms of ascorbic acid equivalent (AAE). This may be due to minimal processing and polishing followed for these rice samples and also genetic inheritance of quality of traditional rice varieties making them more preferred over high yielding varieties among the populations.

\section{Relationship between total polyphenol content (TPC) and total antioxidant capacity (TAC)}

The regression analysis was done to quantify the relationship between TPC and TAC by plotting scatter diagram and linear regression line (Fig. 2). The regression equation for the linear model was $y=4.588 x+39.85$. The final model has used ' $x$ ' (TPC) as the predictor variable and ' $y$ ' (TAC) as explained variable. The coefficient or slope is 4.588, which indicates that, for every unit of TPC, the TAC increases on average by 4.588 points. The value of $\mathrm{R}^{2}=0.931$ which means the model is adequate. It is evident from the findings that 93.1 per cent of the variation in TAC is explained by TPC.

The correlative analysis was also done in this study and a highly positive correlation ( $\mathrm{r}=$ $\left.0.965^{* *}, \mathrm{p}<0.01\right)$ between TPC and TAC values of the tested traditional rice varieties was established, clearly indicating that the higher TPC value resulted in higher TAC value. This suggested that, the phenolic compounds in the tested rice varieties were largely responsible for their total antioxidant capacity. Similar association between TPC and TAC was observed by Gunaratne et al., (2013) in traditional red grained rice varieties of Sri Lanka. Many previous reports also showed that phenolic compounds were major antioxidant constituents in cereals, medicinal herbs, vegetables, fruits, and spices (Liu, 2004; Shan et al., 2005; Cai et al., 2006; Shen et al., 2009).

The results of this study demonstrated a wide range of phytochemical composition and antioxidant activity among traditional rice varieties, which provided the basic information for future development of food applications using these varieties. Traditional rice varieties are better source of phytochemicals and antioxidants. Phytochemicals namely, phytic acid, tannic acid and total polyphenol content were studied in twenty traditional rice varieties varied significantly $(\mathrm{p}<0.05)$ from 236.94 to $558.67 \mathrm{mg}, 25.74$ to $56.88 \mathrm{mgGAE}$, and 47.82 to $160.71 \mathrm{mg}$ per $100 \mathrm{~g}$ respectively. The results in this study clearly showed that traditional rice varieties possessed significantly $(\mathrm{p}<0.05)$ higher antioxidant capacity expressed in terms of ascorbic acid equivalent (AAE). Hence there is a need to popularize these varieties through enhanced production and processing, so that common man can consume phytochemical rich food to get better nutrition.

\section{References}

Ahuja, U., Ahuja, S. C., Chaudhary, N., and Thakrar, R. 2007. Red rices - Past, present and future. Asian Agri. History. 11, 291-304.

Almana, H. A., 2000. Extent of phytate degradation in breads and various foods consumed in Saudi Arabia. Food Chem. 70, 451-456.

Bocevska, M., Aldabas, I., Andreevska, D. and Ilieva, V. 2009. Gelatinization behaviour of grains and flour in relation 
to physiochemical properties of milled rice (Oryza Sativa L.). J. Food Quality. 32, 108-124.

Brand-Williams, W., Cuvelier, M. E. and Berset, C. 1995. Use of a free radical method to evaluate antioxidant activity. Food Sci. Technol. 28, 25-30.

Cai, Y. Z., Sun, M., Xing, J., Luo, Q., and Corke, H. 2006. Structure-radical scavenging activity relationships of natural phenolic compounds from traditional Chinese medicinal plants. Life Sci. 78, 2872-2888.

Dong, M. H., Sang, D. Z., Wang, P., Wang, X. M. and Yang, J. C. 2007. Changes in cooking and nutrition qualities of grains at different positions in a rice panicle under different nitrogen levels. Rice Sci. 14, 141-148.

Dutta, A. K., Gope, P. S., Banik, S., Makhnoon, S., Siddiquee, M. A. and Kabir, Y. 2012. Antioxidant properties of ten high yielding rice varieties of Bangladesh. Asia. Pac. J. Trop. Biomed. 18(2): 99-103.

FAO 2001. Specialty rices of the world. Food and Agriculture Organization of the United Nations, Rome, Italy.

Finocchiaro, F., Ferrari, B., Gianinetti, A., Dall'asta, C., Galaverna, G. and Scazzina, F. 2007. Characterization of antioxidant compounds of red and white rice and changes in total antioxidant capacity during processing. Molecular Nutr. Food Res. 51, 1006-1019.

Finocchiaro, F., Ferrari, B., and Gianinetti, A. 2010. A study of biodiversity of flavonoid content in the rice caryopsis evidencing simultaneous accumulation of anthocyanins and proanthocyanidins in a black-grained genotype. J. Cereal Sci. 51, 28-34.

Gunaratne, A., Wub, K., Li, D. C., Bentota, A. D., Corke, H. B. and Cai, Y. 2013. Antioxidant activity and nutritional quality of traditional red-grained rice varieties containing proanthocyanidins. Food Chem. 138(3): 1153-1161.

IRRI (International Rice Research Institute). 1993. Grain structure, composition and consumer's criteria for quality. In: Rice in human nutrition. Juliano, B. O., ed. Food and Agriculture Organization of the United Nations, Rome. 35-61.

Lee, B. W., Lee, J. H., Lee, S. T., Lee, H. S., Lee, W. S., Jeong, T. S. and Park K. H. 2005. Antioxidant and cytotoxic activities of xanthones from Cudrania tricuspidata Bioorg. Med. Chem. Lett. $15,5548-5552$.

Liang, J., Li, Z., Tsuji, K., Nakano, K., Nout, M. J. R. and Hamer R. J. 2008. Milling characteristics and distribution of phytic acid and zinc in long, medium and short grain rice. J. Cereal Sci. 48(1): 83-91.

Liu, R. H. 2004. Whole grain phytochemicals and health. J. Cereal Sci. 46, 207-219.

Min, B., Mcclung, A. M. and Chen, M. H. 2011. Phytochemicals and antioxidant capacities in rice brans of different colour. J. Food Sci. 76(C): 117-C126.

Mohan, B. H., Malleshi, N. G.and KosekI, T. 2010. Physico-chemical characteristics and non-starch polysaccharide contents of indica and japonica brown rice and their malts. Food Sci. Technol. 43(5): 784-791.

Moongngarm, A. 2010. Influence of germination conditions on starch, physicochemical properties, and microscopic structure of rice flour. International Conference on Biology Env. Chem. IPCBEE. 1, 78-82.

Qureshi, A. A., Mo, H., PackeR, L. and Peterson, D. M. 2000. Isolation and identification of novel tocotrienols from rice bran with hypocholesterolemic, antioxidant, and antitumor properties. J. Agri. Food Chem. 48, 3130-3140.

Rahman, S., Sharma, M. P. and Sahai, S. 2006. Nutritional and medicinal values of some indigenous rice varieties. 
Indian J. Tradit. Know. 5(4): 454-458.

Sadasivam, S. and Manickam, A. 1991. Biochemical methods. Second edition. New Age International Publishers.

Saikia, S., Dutta, H., Saikia, D. and Mahanta, C. L. 2012. Quality characterization and estimation of phytochemicals content and antioxidant capacity of aromatic pigmented and non-pigmented rice varieties. Food Res. Int. 46(2): 334 340.

Shallan, M. A., El-Beltagi, H. S., Mona, A. M. and Amera, T. M. 2010. Chemical evaluation of pre-germinated brown rice and whole grain rice bread. Elec. J. Env. Agricult. Food Chem. 9(5): 958-971.

Shan, B., Cai, Y. Z., Sun, M. and Corke, H. 2005. Antioxidant capacity of 26 spice extracts and characterization of their phenolic constituents. J. Agric. Food Chem. 53. 7749-7759.

Shao, Y., Xu, F., Sun, X., Bao, J. and Beta, T. 2014. Phenolic acids, anthocyanins, and antioxidant capacity in rice (Oryza sativa L.) grains at four stages of development after flowering. Food Chem. 143(4): 90-96.

Shen, Y., Jin, L., Xiao, P., Lu, Y. and Bao, J. S. 2009. Total phenolics, flavonoids, antioxidant capacity in rice grain and their relations to grain colour, size and weight. J. Cereal Sci. 49(1): 106-111.

Tan, F., Dai, W. and Hsu, K. 2009. Changes in gelatinization and rheological characteristics of japonica rice starch induced by pressure/heat combinations.
J. Cereal Sci. 49(2): 285-289.

Trinidad, T. P., Mallillin, A. C., Sagum, R. S., Briones, D. P., Encabo, R. R. and Juliano, B. O. 2009. Iron absorption from brown rice/brown rice-based meal and milled rice/milled rice-based meal. Int. J. Food Sci. Nutr. 60(8): 688-93.

USDA (United States Department of Agriculture) Agricultural Research Service. 2010. USDA nutrient database for standard reference. http://www.ars.usda.gov/services/docs.h tm?docid $=8964 . \mathrm{u}$

Wanyo, P., Chommawang, C. and Siriamornpun, S. 2009. Substitution of wheat flour with rice flour and rice bran in flake products: Effects on chemical, physical and antioxidant properties. World Appl. Sci. J. 7(1): 49-56.

Xu, Z., Hua, N. and Godber, J. S. 2001. Antioxidant activity of tocopherols, tocotrienols and $\gamma$-oryzanol components from rice bran against cholesterol oxidation accelerated by 2, 2-azobis (2methylpropionamidine)

dihydrochloride. J. Agric. Food Chem. 49: 2077-2081.

Yokoyama, W. 2004. Nutritional properties of rice bran. In E. T. Champagne (Ed.), St. Paul, MN: American Association of Cereal Chemist. Rice Chem. Technol. 595-609.

Zhu, F., Cai, Y. Z., Bao, J., and Corke, H. 2010. Effect of $\gamma$-irradiation on phenolic compounds in rice grain. Food Chem. 120, 74-77.

\section{How to cite this article:}

Gopika C. Muttagi and Usha Ravindra. 2020. Phytochemical and Antioxidant Capacity of Traditional Rice Varieties of Karnataka, India. Int.J.Curr.Microbiol.App.Sci. 9(05): 67-75. doi: https://doi.org/10.20546/ijcmas.2020.905.006 